\title{
A focus group study on breast cancer risk presentation: one format does not fit all
}

\author{
Michel Dorval ${ }^{\star 1,2,3}$, Karine Bouchard ${ }^{2,3}$, Jocelyne Chiquette ${ }^{2,3}$, Gord Glendon ${ }^{4}$, Christine M Maugard ${ }^{5,6,7}$, \\ Wilhelm Dubuisson ${ }^{2}$, Seema Panchal ${ }^{8,9}$ and Jacques Simard ${ }^{10,11}$
}

Identifying a strategy that would optimize both the communication and understanding of the individual breast cancer risk remains a considerable challenge. This study explored the preferences of women with a family history of breast cancer about six presentation formats of individual breast cancer risk, as calculated from a risk prediction model. Thirty-four unaffected women attending genetic counseling because of a family history of breast cancer participated in six focus groups conducted in Québec City (2), Montréal (2) and Toronto (2), Canada. Six risk formats were presented for a fictitious case involving a 35-year-old woman (1-numerical: cumulative risk probabilities by age until 80 years; 2-risk curves: probabilities expressed in a risk curve that also provided a risk curve for a woman with no family history in first-degree relatives; 3-relative risk of breast cancer by age 80 years; 4 and 5-absolute risk of breast cancer and absolute chance of not developing breast cancer in the next 20 years; 6-qualitative: color-coded figure). Participants were asked to indicate their appreciation of each format. A group discussion followed during which participants commented on each format. The most and least appreciated formats were risk curves and relative risk, respectively. Overall, participants advocated the use of formats that combine quantitative, qualitative and visual features. Using a combination of approaches to communicate individual breast cancer risks could be associated with higher satisfaction of counselees. Given the increasing use of risk prediction models, it may be relevant to consider the preferences of both the counselee and the professional.

European Journal of Human Genetics (2013) 21, 719-724; doi:10.1038/ejhg.2012.248; published online 21 November 2012

Keywords: risk assessment; health communication; breast neoplasm; probabilities; qualitative research; preferences

\section{INTRODUCTION}

The promises of personalized medicine have contributed to the development of a growing number of disease risk prediction models, ${ }^{1}$ including those for breast cancer risk assessment. ${ }^{2,3}$ Despite some limitations, such tools are useful to tailor screening and support decision making about preventive or treatment options. ${ }^{4}$ Other than the relatively rare, clear-cut situations where deleterious mutations are found in BRCA1/2 or other breast cancer susceptibility genes, screening recommendations for women with a family history of breast cancer are generally based on information provided by such risk prediction tools. ${ }^{1,5}$

Risk is a difficult concept to grasp for most lay individuals, as they do not think in terms of probabilities, ${ }^{6,7}$ which is the core information provided by most risk prediction tools. ${ }^{4,8-10}$ However, there is still no consensus on how to present individualized risk information to consulting patients. ${ }^{6,11,12}$ Thus, identifying a strategy that would optimize the transmission of risk information by health professionals and enhance understanding of individual breast cancer risk remains a considerable challenge. To the best of our knowledge, no study has yet assessed the most effective strategies to communicate probabilities obtained from currently available breast cancer risk prediction models. This study explored the preferences of women with a family history of breast cancer about a number of presentation formats of individual breast cancer risk, as calculated from a risk prediction model.

\section{METHODS}

Participants

This is a qualitative study based on data collected during six focus group sessions conducted in Québec City (2), Montréal (2) and Toronto (2), Canada. Eligible participants were unaffected women who underwent genetic counseling in a familial cancer clinic because of a family history of breast cancer. Given our interest in the perceptions of women about cancer risk presentation formats derived from a risk prediction model, as opposed to risk estimated from gene mutation status per se, women from BRCA1/2 mutation-positive families who had previously received either a positive or true negative test result were ineligible for participation. Therefore, the focus groups included women with an inconclusive BRCA1/2 test result and women not opting for genetic testing following genetic counseling.

Eligible participants were identified through familial cancer clinics from the following centers: CHU de Québec, Hôpital du Saint-Sacrement (Québec City); Centre hospitalier de l'Université de Montréal (CHUM) (Montréal); Marvelle Koffler Breast Center, Mount Sinai Hospital Joseph and Wolf Lebovic

${ }^{1}$ Faculté de pharmacie, Pavillon Ferdinand-Vandry, Université Laval, Québec, QC, Canada; ${ }^{2}$ URESP, Centre de recherche du CHU de Québec, Hôpital du Saint-Sacrement, Québec, QC, Canada; ${ }^{3}$ Centre des maladies du sein Deschênes-Fabia, CHU de Québec, Hôpital du Saint-Sacrement, Québec, QC, Canada; ${ }^{4}$ Ontario Cancer Genetics Network, Samuel Lunenfeld Research Institute, Mount Sinai Hospital, Toronto, ON, Canada; ${ }^{5}$ CRCHUM and Département de médecine, Université de Montréal, Montréal, QC, Canada; ${ }^{6}$ Service de médecine génique, Hôtel Dieu, CHUM, Montréal, QC, Canada; ${ }^{7}$ Laboratoire de Diagnostic Génétique, Hôpitaux Universitaires de Strasbourg, Strasbourg, France; ${ }^{8}$ Familial Breast Cancer Clinic, Mount Sinai Hospital, Toronto, ON, Canada; ${ }^{9}$ Department of Medical Genetics and Microbiology, University of Toronto, Toronto, ON, Canada; ${ }^{10}$ Département de médecine moléculaire, Faculté de médecine, Pavillon Ferdinand-Vandry, Université Laval, Québec, QC, Canada; ${ }^{11}$ Laboratoire de génomique des cancers, Centre de recherche du CHU de Québec CHUL, Québec, QC, Canada

*Correspondence: Professor M Dorval, Unité de recherche en santé des populations, Centre de recherche du CHU de Québec, Hôpital du Saint-Sacrement, 1050 chemin Sainte-Foy, Québec City, QC G1S 4L8, Canada. Tel: + 1 (418) 6828047; Fax: + 1 (418) 6827949; E-mail: mdorval@uresp.ulaval.ca

Received 31 May 2012; revised 17 September 2012; accepted 11 October 2012; published online 21 November 2012 
Health Complex (Toronto). To ensure the focus groups represented a diversity of experiences and perceptions, particular attention was given to selecting women of different ages with diverse family histories of breast cancer. Eligible patients were invited to participate primarily by telephone (Québec City and Montréal) or via mail (Toronto). Telephone calls were conducted by a nurse, genetic counselor or research associate. In the weeks preceding the focus group, women interested in participating were mailed an informed consent form to sign and a brief self-administered questionnaire with a pre-paid return envelope. Each participant received \$60 CA in compensation. The study was approved by the Research Ethics Committee of each participating center.

\section{Data collection}

The self-administered questionnaire collected data about family history of cancer, knowledge of breast cancer risk factors, perception of the risk of developing breast cancer and basic sociodemographic information.

The focus group process was similar in each center, except that the discussions were carried out in French in Québec City and Montréal and in English in Toronto. A very experienced female professional moderator from a private research firm led all the groups using a semi-structured guide designed by the research team. The moderator was hired on a contractual basis and is not a co-author of this article. The focus group sessions were held in rooms especially equipped for the purpose; the discussions were videotaped and transcribed. Participants were informed about the study objectives and the fact that two research team members and a research associate from a private firm observed the focus group session behind a one-way mirror to record field notes during the group discussion. ${ }^{13}$ Each focus group lasted about 2 hours.

Participants were first asked to introduce themselves briefly to the others. A fictitious case of a woman with a familial cancer history was then presented (Figure 1), followed by a PowerPoint presentation (and handouts) describing the six formats of the woman's estimated risk of breast cancer. The risk estimate, as calculated by the BOADICEA algorithm, ${ }^{8,9}$ was presented in all the six formats. After each format presentation, participants were asked to individually rate their appreciation of that format on a scale of 1-10. A group discussion followed and participants commented on each format, justifying their score. As reflected in the typical questions (see Supplementary Appendix 1 online) used by the moderator during the focus group sessions, appreciation was conceptualized as a mixture of likeability, clarity, perceived risk understanding and emotional impact. Once all formats were discussed, participants were asked to indicate their overall preferred risk presentation format.

\section{Risk presentation formats}

We selected risk presentation formats that are frequently used by health professionals based on a systematic overview of the literature on risk communication in the context of familial breast cancer and on a careful analysis of nearly 100 risk communication tools used by cancer genetics clinics around the world (manuscripts in preparation). We were also specifically interested in getting women's views about how the BOADICEA prediction model provides risk estimates online to the general population. Due to time limitations, six risk formats were presented to participants for the purpose of self-evaluation and discussion (Figure 2). The first format, referred to here as the numerical format, is derived from the BOADICEA risk prediction model, which presents cumulative breast cancer risk probabilities at four decimal levels by age, from the current age of the fictitious case (35) until 80 years (Figure 2a). These probabilities were then expressed in a risk curve format, which also provided a breast cancer risk curve for a woman of the same age with no family history in first-degree relatives (Figure $2 \mathrm{~b}$ ). The third format was expressed as the relative risk of developing breast cancer by age 80 years (Figure 2c). The fourth and fifth formats presented the absolute risk of developing breast cancer in the next 20 years and the absolute chance of not developing breast cancer during the same period, respectively (Figure $2 \mathrm{~d}$ and $2 \mathrm{e}$ ). The last risk format was qualitatively presented in words, using a color-coded figure (Figure 2f).

\section{Analysis}

The mean appreciation score was first calculated for each risk presentation format. The proportion of women choosing each format as their preference was also calculated. To enable a synthesis of the participants' views on each risk

A 35 years old woman, mother of two children is concerned about of her breast cancer risk. In the last 5 years, her mother was diagnosed with breast cancer, her sister died of ovarian cancer at 45 , and one of her aunts died of breast cancer. Her personnal and familial medical histories were used to calculate her breast cancer risk using a mathematical model.

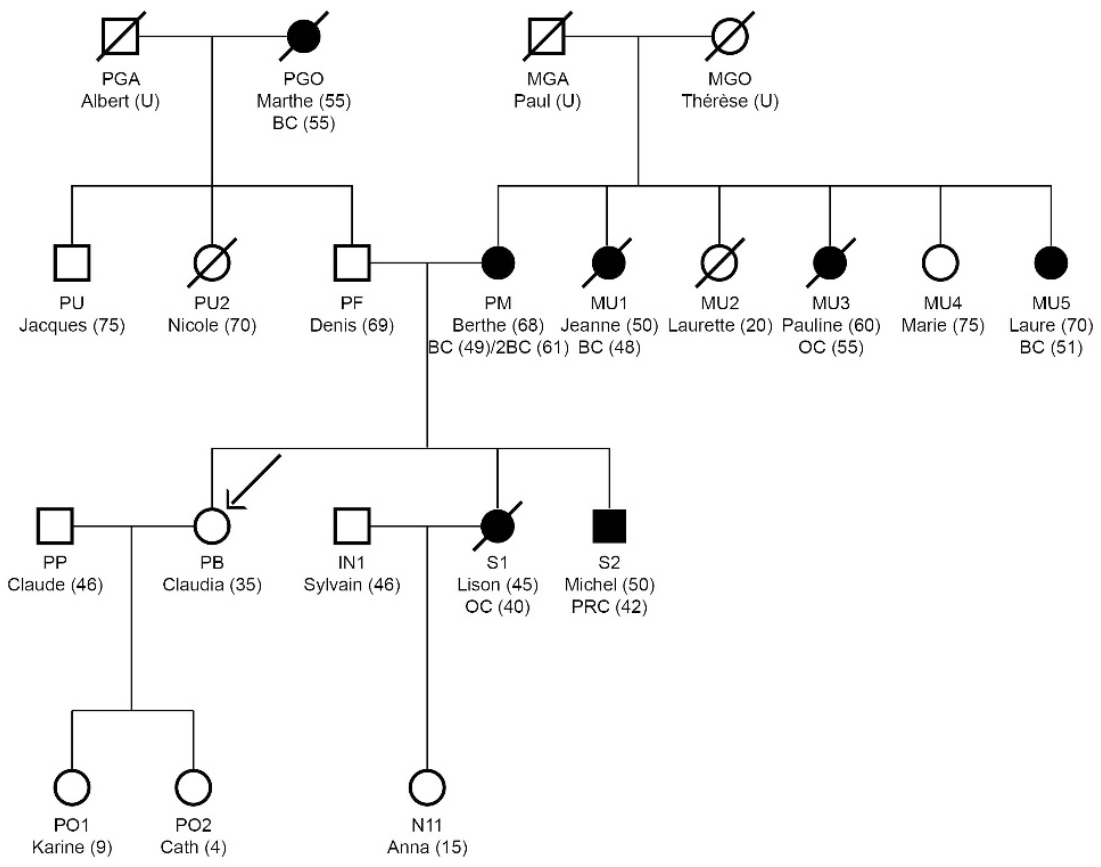

Figure 1 Case description and pedigree of the fictitious case. 
a

\begin{tabular}{|lcc|}
\hline \multicolumn{3}{c}{ Numerical format } \\
\hline Age & $\begin{array}{c}\text { Breast } \\
\text { cancer risks }\end{array}$ & $\begin{array}{c}\text { Ovarian } \\
\text { cancer risks }\end{array}$ \\
36 & 0.0063 & 0.0005 \\
37 & 0.0132 & 0.0012 \\
38 & 0.0206 & 0.0022 \\
39 & 0.0285 & 0.0035 \\
40 & 0.0367 & 0.0053 \\
45 & 0.0857 & 0.0185 \\
50 & 0.1447 & 0.0342 \\
55 & 0.2028 & 0.0534 \\
60 & 0.2520 & 0.0761 \\
65 & 0.2914 & 0.0976 \\
70 & 0.3232 & 0.1174 \\
75 & 0.3503 & 0.1355 \\
80 & 0.3729 & 0.1513 \\
\hline
\end{tabular}

\section{C}

Claudia is approximately 2.3 times more at risk of developing breast cancer at 80 years old than a woman with no family history of cancer in first degree relatives. b

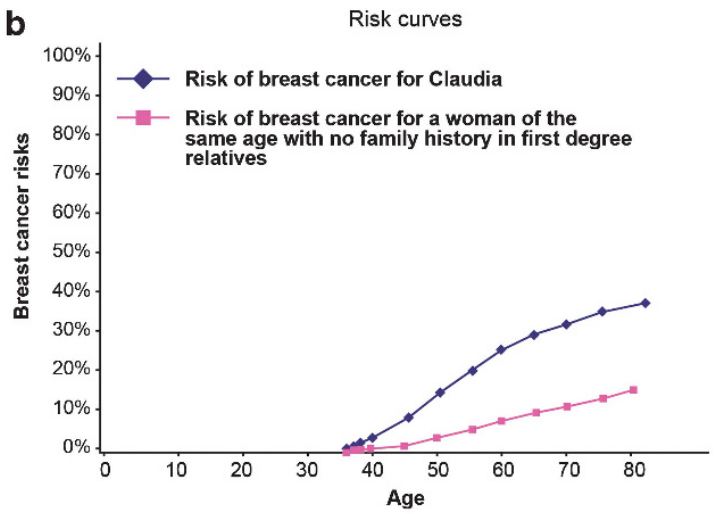

d Absolute risk

The risk of Claudia of developing breast cancer between now and the next 20 years is approximately $20 \%$.

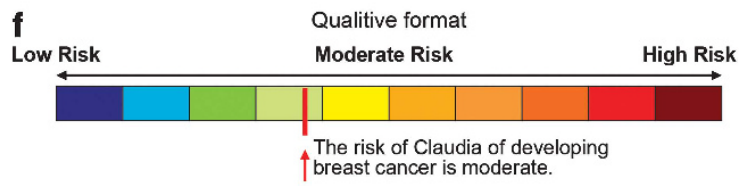

Figure 2 Risk presentation formats used for self-evaluation and group discussions.

presentation format, a note-based analysis was performed on the discussion content following the techniques suggested by Krueger and Casey (2009). ${ }^{13}$ The analysis, performed by the assistant moderator and cross-validated by the research team, identified the points of convergence and divergence among the groups. Video recordings of the discussions were available during the analysis, as necessary.

\section{RESULTS}

Of the 111 women who met eligibility criteria in the three sites, a total of 34 women $(31 \%)$ participated in the six focus groups (Table 1 ). The main reasons for non-participation were unavailability at the time of the scheduled focus group sessions and lack of interest. Age varied substantially within the groups with a mean of 45 years. Approximately half had a university degree, and most were currently employed and had children. The majority had at least one first-degree relative affected by breast cancer and half perceived their own risk of developing breast cancer as high or very high.

The risk curves format received the highest appreciation score and was the majority preference (Table 2). By contrast, the relative risk format was the least appreciated and was not the preferred format of any participant. The other formats received similar mean appreciation scores. The qualitative format was the second highest preferred format and the preference of $20 \%$ of participants. Specific opinions on each format expressed during the focus groups, and summarized hereafter, varied little among the study sites.

\section{Numerical format}

Opinions on this format were generally negative. Most participants felt it lacked clarity, was too numerical and provided no basis of comparison. On this last point, it was generally reported that without knowing an average person's risk, these probabilities provided few insights, limiting understanding and increasing confusion. Based on the complexity and abundance of numbers, participants felt that this format was more suitable to doctors than patients: 'I think if you're giving this to a person who has no medical experience or no anything, this would be too freaky for them' (Group A, Toronto).

\section{Risk curves}

For most participants, this format provided clear information and was easily understood. Presentation of comparative data about the average risk of similarly-aged women without a familial cancer history was greatly appreciated. Most participants qualified it as a good combination of high clarity and multiple comparison measures: 'I like the instant visual comparison that lets you know where you stand versus other people' (Group A, Toronto). Nevertheless, some felt that a qualitative interpretation should be added to describe the gap between the patient's risk and that of a woman without a family history, to better understand how to interpret this difference.

\section{Relative risk}

This format inspired very few positive comments and was strongly criticized in all the groups. Despite stating that the fictitious case was '2.3 times more likely to develop breast cancer', many participants wondered how that translated in absolute terms: 'It doesn't mean anything to me. 2.3 times more doesn't have any quantitative value to me. I wouldn't know how to gauge it, ie if it's high or not' (Group B, Toronto). Inferences in this regard remained open to interpretation. For some, 2.3 times seemed like a lot, whereas for others it did not. Furthermore, the fact that age 80 years was used as the time-frame made many women feel unconcerned with the associated risk. For most, 80 years was simply too far in the future, and they seemed more concerned about what was likely to happen to them within the next 5 to 10 years: 'Me, I scored it 4, because it tells me nothing... I don't care about what will happen in 50 years. It's too far ... I'd rather have an idea of what can happen before that' (Group B, Québec City). This format was also criticized for lack of a visual component. 
Table 1 Characteristics of participants

\begin{tabular}{|c|c|c|c|c|c|c|c|c|c|c|c|c|c|c|}
\hline Characteristic & \multicolumn{4}{|c|}{ Québec $\mathrm{n}=11$} & \multicolumn{4}{|c|}{ Montréal $\mathrm{n}=9$} & \multicolumn{4}{|c|}{ Toronto $\mathrm{n}=14$} & \multicolumn{2}{|c|}{ Total $\mathrm{n}=34$} \\
\hline \multicolumn{15}{|l|}{ Age (years) } \\
\hline$\leq 39$ & 2 & (29) & 1 & (25) & 2 & (33) & 1 & (33) & 2 & (22) & 2 & $(40)$ & 10 & (30) \\
\hline University degree completed & 4 & (57) & 4 & $(100)$ & 2 & (33) & 2 & (67) & 3 & (33) & 3 & $(60)$ & 18 & (53) \\
\hline Currently employed & 6 & (86) & 3 & $(75)$ & 5 & (83) & 1 & (33) & 7 & (78) & 4 & $(80)$ & 26 & (76) \\
\hline Living with a spouse & 7 & $(100)$ & 1 & $(25)$ & 5 & (83) & 1 & (33) & 6 & $(67)$ & 2 & $(40)$ & 22 & (65) \\
\hline Children & 5 & (71) & 3 & (75) & 5 & (83) & 3 & $(100)$ & 7 & (78) & 3 & $(60)$ & 26 & (76) \\
\hline Caucasian (Ashkenazi Jew) & 0 & $(0)$ & 0 & (0) & 0 & (0) & 0 & $(0)$ & 1 & $(11)$ & 0 & (0) & 1 & (3) \\
\hline \multicolumn{15}{|c|}{ Lifetime breast cancer risk perception } \\
\hline High or very high & 5 & (71) & 1 & (25) & 5 & (83) & 1 & (33) & 3 & (33) & 2 & $(40)$ & 17 & $(50)$ \\
\hline Moderate & 2 & (29) & 3 & $(75)$ & 1 & (17) & 2 & (67) & 4 & $(44)$ & 2 & $(40)$ & 14 & $(41)$ \\
\hline Low or very low & 0 & $(0)$ & 0 & $(0)$ & 0 & $(0)$ & 0 & $(0)$ & 2 & (22) & 1 & (20) & 3 & (9) \\
\hline \multicolumn{15}{|c|}{ Family history (first-degree relatives) } \\
\hline Breast cancer 0 & 2 & (29) & 2 & $(50)$ & 0 & (0) & 0 & $(0)$ & 3 & (33) & 2 & $(50)$ & 9 & (27) \\
\hline Breast cancer 1 & 3 & (42) & 1 & (25) & 5 & (83) & 1 & (33) & 6 & $(67)$ & 2 & $(50)$ & 18 & (55) \\
\hline Breast cancer $\geq 2$ & 2 & (29) & 1 & $(25)$ & 1 & (17) & 2 & (67) & 0 & $(0)$ & 0 & (0) & 6 & (18) \\
\hline
\end{tabular}

aBecause of missing data, the number of participants does not always add up to the total.

Table 2 Participants' appreciation of the risk presentation formats

\begin{tabular}{lccc}
\hline & Mean appreciation score & \multicolumn{2}{c}{$\begin{array}{c}\text { Participants who selected each } \\
\text { format as their preference }\end{array}$} \\
\cline { 3 - 4 } & & $\mathrm{n}$ & $(\%)$ \\
\hline Numerical format & 5.6 & 4 & $(12)$ \\
Risk curves & 7.4 & 19 & $(56)$ \\
Relative risk & 3.9 & 0 & $(0)$ \\
Absolute risk & 5.6 & & \\
Absolute chance & 5.4 & $4^{\mathrm{b}}$ & $(12)$ \\
Qualitative risk & 5.1 & 7 & $(21)$ \\
\hline
\end{tabular}

aRange from 1 (least appreciated) to 10 (most appreciated).

bThe absolute risk and absolute chance formats were considered together when asking about preferred format.

\section{Absolute risk/chance}

Some participants appreciated the directness and clarity of the riskfocused message. Others felt it was excessively definitive in tone and portrayed an overly negative result. With respect to the absolute chance format, a number of women felt that it was like looking at the glass half full and the message was not clear enough to generate a positive appreciation. Some women liked the positive spin, but others felt that it offered a false sense of security and, in this manner, was actually too positive. Lacking comparison, the absolute risk and absolute chance formats were also viewed by some as confusing and open to misinterpretation: 'I think it complicates the reading of the sentence because what you remember is 'cancer, 80\%, 20 years'
(Group A, Montréal). For some, 20 years was too far in the future to worry about or to be reassured.

\section{Qualitative risk}

Participants' held widely contrasting views about this format. Women who did not want detailed information about their breast cancer risk were more likely to appreciate a qualitative risk presentation format, which they felt portrayed breast cancer risk in a positive, less distressing manner and made it clear where the patient stood on the broad spectrum. For other women, particularly those who value more detailed information, the scale was not clear enough and imprecise due to the absence numerical and comparative data. 'I like the colors, but the numbers are missing. Just saying the risk is moderate is rather vague'. (Group A, Montréal).

Overall, participants advocated for formats that combined quantitative, qualitative and visual components. Some women felt that even the majority preference format, the curves, would be more complete if values and qualitative interpretations were provided. Suggestions related to the numerical format also included the addition of a qualitative summary of the information. A number of women further stated that risk presentation formats could benefit from the addition of methodological information, such as sample size, study population, authors and date, among others, to allow a more comprehensive understanding of the risk information provided.

\section{DISCUSSION}

To our knowledge, this is the first study to explore the perspectives of women at moderate to potentially high risk of breast cancer with 
respect to various presentation formats of individual risks, as calculated from a risk prediction model. Although the risk curves format was clearly the majority preference, our findings also suggest that using a combination of approaches to communicate individual risks could be associated with higher satisfaction of counselees. In particular, crude probabilities should be presented in a simpler format or using multiple approaches that include a visual component.

Women's opinions regarding relative risk and cumulative probabilities, presented here in the numerical format, are consistent with those reported in previous studies. ${ }^{14-16}$ As reported by some participants, numerical risk presentations are difficult to understand and can lead to inaccurate risk perception..$^{6,14,17,18}$ It is well-known that the translation of relative risk to actual likelihood of developing cancer is a difficult task for lay persons, ${ }^{6,7,15,19,20}$ particularly those with low numeracy. ${ }^{21-23}$ This is particularly true for individuals with low numeracy. ${ }^{21-23}$ In Canada, approximately one woman in three is unable to perform the basic mathematical operations needed to understand probabilities. ${ }^{24}$ The figure is similar in other industrialized countries. $^{18,25-27}$ Because health professionals commonly use probabilities and relative risk to provide risk information to their patients, ${ }^{28,29}$ our results suggest that using complementary approaches, such as visual aids, could help a number of patients better grasp their actual risk.

Contrary to what has been found in other medical contexts, presentation of probabilistic information as a gain, or chance, was not associated here with a positive appreciation. ${ }^{16}$ In the context of genetic counseling for breast cancer susceptibility, the emphasis of risk communication is usually placed on the possible occurrence of the disease rather than its absence, a phenomenon sometimes referred to as problem-oriented probability. ${ }^{17,29}$ Because positive framing involves the addition of a negation in the message formulation, it often complicates the processing of risk information. ${ }^{30}$ To avoid any bias introduced by such framing effect, it is argued that risk information should be presented simultaneously in both gain and loss formats, ${ }^{31,32}$ as we have done in this study. It is believed that lownumeracy people are more susceptible to framing than highnumeracy individuals and that visual aids could be an effective method to eliminate its effects. ${ }^{33}$ However, further research is needed to identify which visual aids are most effective in decreasing such framing effects.

The combination of visual and verbal approaches is usually associated with greater satisfaction, better understanding and a more realistic risk perception. ${ }^{11}$ A visual risk presentation facilitates the processing of numeric information..$^{23,31,34-36}$ However, care should be taken when selecting a specific visual format because such a presentation could influence risk interpretation and trigger an emotional response. ${ }^{37}$ As observed during our focus group sessions, the use of non-tailored strategies can generate reassurance, worry or doubt. Nonetheless, the use of formats that prompt anxiety and fear may be justified in certain contexts, such as mass public health communication. ${ }^{38}$

In this study, the women's attitudes to risk presentation formats varied substantially. It can be hypothesized that each participant's coping style was associated with these preferences. ${ }^{39}$ It is well-known that emotional responses to risk communication vary according to a patient's coping style, especially with respect to information seeking. ${ }^{11,40,41}$ So-called monitors need more information to cope with stress than blunters. ${ }^{42}$ In this study, women who appreciated the qualitative risk presentation format indicated that they did not want more detailed information about their breast cancer risk. By contrast, others argued for the addition of methodological information to allow a more comprehensive understanding of the risk information provided. In the context of breast cancer risk assessment, further research is needed to tailor risk communication approaches to individual counselees. ${ }^{11}$

The reporting of this study generally follows recent qualitative research standards. ${ }^{43}$ However, caution is recommended when interpreting the study results. Note that, given the study design, our participants' perspectives may not be representative of all women at moderate-to-high risk of breast cancer. To ensure the focus groups represented the broadest possible diversity of experience and perceptions, the focus group sessions took place in three cities with women of different backgrounds. Nevertheless, because highly educated women may be over-represented in our sample, it is plausible that the crude probabilities and relative risk formats might be less appreciated in a real-life context. This lack of representativeness may also explain why the chance format was apparently less appreciated than suggested in an earlier review. ${ }^{16}$ Another limitation relates to the fact that, due to time constraints, other formats used by health professionals to communicate breast cancer risk could not be presented to study participants for discussion. Nevertheless, we are confident to have selected formats that apply to a significant number of clinical situations. The fact that risk presentation formats differ in some aspects, such as time frame, may be seen as another limitation. People tend to given more weight to outcomes that are closer in time, a phenomenon referred to as the time-discounting bias. ${ }^{44}$ The fact that time frames and certain other aspects were not equally distributed over the formats may confound the participants' evaluations of risk formats. Other limitations relate to the fact that this study assessed opinions on risk presentation formats, rather than global communication strategies that can optimize risk understanding. Although appreciation and understanding are probably related, it is possible that effective strategies to foster risk understanding may not be most appreciated. ${ }^{45}$ Finally, care should be taken when extrapolating our results to other adult-onset hereditary disorders. Indeed, the effectiveness of risk communication does not only depend on how risk information is presented but is also a function of the characteristics of the disorder, including its preventability and consequences. ${ }^{46}$

Taken together, our findings point to the need for conducting research in a larger sample with the main features of risk presentation, such as time frame and context, being standardized and controlled for across formats. Awareness of each woman's preferences, concerns and priorities are key factors for achieving adequate counseling. ${ }^{20,47}$ Until we have a better knowledge of how these factors relate to risk interpretation, and because the women's backgrounds and experiences vary widely, it might be valuable to spend time assessing each woman's preferred risk presentation before adopting a specific strategy. If this is not feasible in clinical settings, it may prove valuable to use a combination of approaches to communicate individual risk rather than using only crude age-probabilities, which is the format used in most online self-risk assessment models ${ }^{9,10,48-50}$ Given the increasing use of, and accessibility to, risk prediction models, our findings highlight the relevance of considering the preferences of both the woman to whom the risk is communicated and the professional.

\section{CONFLICT OF INTEREST}

The authors declare no conflict of interest. 


\section{ACKNOWLEDGEMENTS}

We thank all study participants for the invaluable contribution of their time and effort. We also wish to thank the following people for their ongoing support of this research project: Stéphanie Côté (recruitment), Josée Rhéaume (recruitment), Claudia Côté (data and quality management), Ursula Donovan (linguistic revision), Christine Melançon (moderator) and Tom Rygby (report and analyses) from Ipsos Descarie.

Research support: The research program is supported by the Canadian Institutes of Health Research for the "CIHR Team in Familial Risks of Breast Cancer" program (CIHR; CRN-87521) and the Ministry of Economic Development, Innovation and Export Trade of Quebec (PSR-SIIRI-701); MD held a Fonds de la Recherche en Santé du Québec research Fellowship when this work was done; JS is Chair holder of the Canada Research Chair in Oncogenetics.

1 Weitzel JN, Blazer KR, Macdonald DJ, Culver JO, Offit K: Genetics, genomics, and cancer risk assessment: state of the art and future directions in the era of personalized medicine. CA Cancer J Clin 2011; 61: 327-359.

2 Anothaisintawee T, Teerawattananon Y, Wiratkapun C, Kasamesup V, Thakkinstian A Risk prediction models of breast cancer: a systematic review of model performances. Breast Cancer Res Treat 2011; 133: 1-10.

3 Meads C, Ahmed I, Riley RD: A systematic review of breast cancer incidence risk prediction models with meta-analysis of their performance. Breast Cancer Res Treat 2012; 132: 365-377.

4 Amir E, Freedman OC, Seruga B, Evans DG: Assessing women at high risk of breast cancer: a review of risk assessment models. J Natl Cancer Inst 2010; 102: 680-691.

5 Smith RA, Cokkinides V, Brooks D, Saslow D, Shah M, Brawley OW: Cancer screening in the United States, 2011: a review of current American Cancer Society Guidelines and Issues in Cancer Screening. CA Cancer J Clin 2011; 61: 8-30.

6 Sivell S, Elwyn G, Gaff $C$ et al: How risk is perceived, constructed and interpreted by clients in clinical genetics, and the effects on decision making: Systematic Review. $J$ Genet Couns 2008; 17: 30-63.

7 Davison C, Smith GD, Frankel S: Lay epidemiology and the prevention paradox: the implications of coronary candidacy for health education. Sociol Health III 1991; 13 $1-19$.

8 Antoniou AC, Cunningham AP, Peto $\mathrm{J}$ et al: The BOADICEA model of genetic susceptibility to breast and ovarian cancers: updates and extensions. $\mathrm{Br} J$ Cancer 2008; 98: 1457-1466.

9 Antoniou AC, Pharoah PPD, Smith P, Easton DF: The BOADICEA model of genetic susceptibility to breast and ovarian cancer. Br J Cancer 2004; 91: 1580-1590.

10 Wacholder S, Hartge P, Prentice R et al: Performance of common genetic variants in breast-cancer risk models. N Engl J Med 2010; 362: 986-993.

11 Julian-Reynier C, Welkenhuysen M, Hagoel L, Decruyenaere M, Hopwood P: Risk communication strategies: state of the art and effectiveness in the context of cancer genetic services. Eur J Hum Genet 2003; 11: 725-736.

12 Edwards A, Gray J, Clarke A et al: Interventions to improve risk communication in clinical genetics: systematic review. Patient Educ Couns 2008; 71: 4-25.

13 Krueger R, Casey MA: Focus Groups, a Pratical Guide for Applied Research, 4th edn, Thousand Oaks, CA: Sage Publications, 2009.

14 Cull A, Anderson EDC, Campbell S, Mackay J, Smyth E, Steel M: The impact of genetic counselling about breast cancer risk on women's risk perceptions and levels of distress. Br J Cancer 1999; 79: 501-508.

15 Goodyear-Smith F, Arroll B, Chan L, Jackson R, Wells S, Kenealy T: Patients prefer pictures to numbers to express cardiovascular benefit from treatment. Ann Fam Med 2008; 6: 213-217.

16 Vahabi M: The impact of health communication on health-related decision making $A$ review of evidence. Health Educ 2007; 107: 27-41.

17 Edwards A, Elwyn G, Covey J, Matthews E, Pill R: Presenting risk information: a review of the effects of framing and other manipulations on patient outcomes. J Health Commun 2001; 6: 61-82.

18 Schwartz LM, Woloshin S, Black WC, Welch HG: The role of numeracy in understanding the benefit of screening mammography. Ann Intern Med 1997; 127 966-972.

19 Hutson SP: Attitudes and psychological impact of genetic testing, genetic counseling, and breast cancer risk assessment among women at increased risk. Oncol Nurs Forum 2003; 30: 241-246.

20 Austin J: Re-conceptualizing risk in genetic counseling: implications for clinical practice. J Genet Couns 2010; 19: 228-234.
21 Safeer RS, Keenan J: Health literacy: the gap between physicians and patients. Am Fam Physician 2005; 72: 463-468.

22 Wright AJ, Whitwell SC, Takeichi C, Hankins M, Marteau TM: The impact of numeracy on reactions to different graphic risk presentation formats: an experimental analogue study. Br J Health Psychol 2009; 14: 107-125.

23 Reyna VF, Nelson WL, Han PK, Dieckmann NF: How numeracy influences risk comprehension and medical decision making. Psychol Bull 2009; 135: 943-973.

24 Statistics Canada: Building on our Competencies: Canadian Results of the International Adult Literacy and Skills Survey [Catalogue no. 89-617-XIE], 2003.

25 Galesic M, Garcia-Retamero R: Statistical numeracy for health: a cross-cultural comparison with probabilistic national samples. Arch Intern Med 2010; 170: 462-468.

26 Lipkus IM, Samsa G, Rimer BK: General performance on a numeracy scale among highly educated samples. Med Decis Making 2001; 21: 37-44.

27 Davids SL, Schapira MM, McAuliffe TL, Nattinger AB: Predictors of pessimistic breast cancer risk perceptions in a primary care population. J Gen Intern Med 2004; 19: 310-315.

28 Lobb EA, Butow PN, Meiser B et al: Women's preferences and consultants' communication of risk in consultations about familial breast cancer: impact on patient outcomes. J Med Genet 2003; 40: e56.

29 Pieterse AH, van Dulmen S, van Dijk S, Bensing JM, Ausems MG: Risk communication in completed series of breast cancer genetic counseling visits. Genet Med 2006; 8 688-696.

30 Welkenhuysen M, Evers-Kiebooms G, d'Ydewalle G: The language of uncertainty in genetic risk communication: framing and verbal versus numerical information. Patient Educ Couns 2001; 43: 179-187.

31 Ancker JS, Senathirajah Y, Kukafka R, Starren JB: Design features of graphs in health risk communication: a systematic review. J Am Med Inform Assoc 2006; 13 608-618.

32 Dolan J: The importance of form, content, and context in the design and effectiveness of risk communication methods. Cancer Prev Res 2010; 3, Abstract \# CN15-03, doi:10.1158/1940-6207-10-CN15-03.

33 Garcia-Retamero R, Galesic M: How to reduce the effect of framing on messages about health. J Gen Intern Med 2010; 25: 1323-1329.

34 Schapira MM, Nattinger AB, McAuliffe TL: The influence of graphic format on breast cancer risk communication. J Health Commun 2006; 11: 569-582.

35 Hawley ST, Zikmund-Fisher B, Ubel P, Jancovic A, Lucas T, Fagerlin A: The impact of the format of graphical presentation on health-related knowledge and treatment choices. Patient Educ Couns 2008; 73: 448-455.

36 Lipkus IM, Hollands JG: The Visual Communication of Risk. J Nat/ Cancer Inst Monogr 1999; 25: 149-163.

37 Han PKJ, Klein WMP, Lehman T, Killam B, Massett H, Freedman AN: Communication of uncertainty regarding individualized cancer risk estimates: effects and influential factors. Med Decis Making 2011; 31: 354-366.

38 Noar SM, Mehrotra P: Toward a new methodological paradigm for testing theories of health behavior and health behavior change. Patient Educ Couns 2010; 82: 468-474.

39 Phipps S, Zinn AB, Opitz JM, Reynolds JF: Psychological response to amniocentesis: II. Effects of coping style. Am J Med Genet, 1986; 25: 143-148.

40 Bottorff JL, Ratner PA, Johnson JL, Lovato CY, Joab SA: Communicating cancer risk information: the challenges of uncertainty. Patient Educ Couns 1998; 33: 67-81.

41 Vernon SW: Risk perception and risk communication for cancer screening behaviors: a review. J Nat/ Cancer Inst 1999; 91: 101.

42 Miller SM: Monitoring versus blunting styles of coping with cancer influence the information patients want and need about their disease. Implications for cancer screening and management. Cancer 1995; 76: 167-177.

43 Tong A, Sainsbury P, Craig J: Consolidated criteria for reporting qualitative research (COREQ): a 32-item checklist for interviews and focus groups. Int J Qual Health Care 2007; 19: 349-357.

44 Ortendahl M, Fries JF: Framing health messages based on anomalies in time preference. Med Sci Monit 2005; 11: RA253-RA256.

45 Brown SM, Culver JO, Osann KE et al: Health literacy, numeracy, and interpretation of graphical breast cancer risk estimates. Patient Educ Couns 2011; 83: 92-98.

46 Walter FM, Emery J, Braithwaite D, Marteau TM: Lay understanding of familial risk of common chronic diseases: a systematic review and synthesis of qualitative research. Ann Fam Med 2004; 2: 583-594.

47 Ellington L, Kelly KM, Reblin M, Latimer S, Roter D: Communication in genetic counseling: cognitive and emotional processing. Health Commun 2011; 26: 667-675.

48 Gail MH, Brinton LA, Byar DP et al: Projecting individualized probabilities of developing breast cancer for White females who are being examined annually. J Nat Cancer Inst 1989; 81: 1879-1886.

49 Rockhill B, Spiegelman D, Byrne C, Hunter DJ, Colditz GA: Validation of the Gail et al model of breast cancer risk prediction and implications for chemoprevention. J Nat Cancer Inst 2001; 93: 358-366.

50 Gail MH, Mai PL: Comparing breast cancer risk assessment models. J Natl Cancer Inst 2010; 102: 665-668.

Supplementary Information accompanies the paper on European Journal of Human Genetics website (http://www.nature.com/ejhg) 